\title{
Early Ethnic Difference in Insulin-Like Growth Factor-1 Is Associated with African Genetic Admixture
}

\author{
PAUL B. HIGGINS, JOSÉ R. FERNÁNDEZ, MICHAEL I. GORAN, AND BARBARA A. GOWER \\ Department of Nutrition Sciences and the Clinical Nutrition Research Center [P.B.H., J.R.F., B.A.G.], \\ University of Alabama at Birmingham, Birmingham, Alabama 35294; Departments of Preventive Medicine \\ and Physiology and Biophysics [M.I.G.], University of Southern California, Los Angeles, California 90033
}

\begin{abstract}
IGF-1 is a growth-promoting hormone. Numerous studies have reported higher systemic concentrations of IGF-1 among African Americans (AA) compared with European Americans (EA) before puberty. We conducted this cross-sectional analysis to determine whether African ancestral genetic background, dietary factors, energy expenditure, adiposity, and socioeconomic status contribute to this difference. Children were prepubertal, $\mathrm{AA}$ and EA males and females. Genetic admixture was assessed from $\sim 20$ ancestry informative genetic markers. Body composition was determined by dual-energy x-ray absorptiometry; intake of energy, carbohydrate, protein, and fat by 24-h dietary recall; activity-related energy expenditure by doubly labeled water and indirect calorimetry; and socioeconomic status (SES) according to the Hollingshead scale. IGF-1 and IGF binding protein-3 (IGFBP-3) were measured using immunoradiometric assays. AA children had significantly greater IGF-1 compared with EA children $(p<0.01)$. In addition, AA children had lower
\end{abstract}

\section{ABSTRACT}

SES and greater protein intake relative to EAs $(p<0.05$ for both). Multiple linear regression analysis revealed that the only significant independent predictors of IGF-1 were IGFBP-3 and African admixture ( $p<0.01$ for both). Thus, our data suggest that the greater IGF-1 of AA relative to EA children could have a genetic basis. (Pediatr Res 58: 850-854, 2005)

Abbreviations
AA, African American
AEE, activity-related energy expenditure
AFADM, African admixture
EA, European American
GH, growth hormone
IGF-1, insulin-like growth factor-1
IGFBP-3, insulin-like growth factor binding protein-3
SES, socioeconomic status

IGF-1 is a potent anabolic peptide that is present in the systemic circulation and is expressed in most body tissues. Thus, the peptide has both endocrine and autocrine/paracrine actions (1). Its systemic and tissue concentrations are regulated by numerous factors including growth hormone $(\mathrm{GH})$ and an array of binding proteins. IGFBP-3 is the dominant regulator of systemic IGF-1 bioavailability, binding the majority of the circulating peptide (1). Because of its potency and ubiquity within the body, IGF-1 is considered an important endogenous

Received December 22, 2004; accepted April 18, 2005.

Correspondence: Paul B. Higgins, Department of Nutrition Sciences, 1675 University Blvd., RM 423, University of Alabama at Birmingham, Birmingham, AL 35294; e-mail: higginsp@uab.edu

Supported by National Institutes of Health grants R01-DK49779 and R01-DK-51684, General Clinical Center Grant M01-RR00032, and Clinical Nutrition Research Unit Grant P30-DK56336. P.B.H. is supported in part by the Buris R. Boshell Scholarship in Medicine from the Diabetes Trust Fund of Alabama.

These data were presented in part as a poster at the North American Association for the Study of Obesity annual meeting, Fort Lauderdale, FL, 2003.

DOI: 10.1203/01.PDR.0000182583.92130.08 growth-promoting agent. However, IGF-1 is also associated with numerous disorders, including cancer $(2,3)$.

Several studies have shown that AA children have higher systemic concentrations of IGF-1 compared with EA children (4-6). Most studies suggest that this difference does not track into adulthood $(7,8)$, but some data do indicate higher concentrations in AA compared with EA adults (9). The physiologic basis for higher IGF-1 among AAs is not known. An obvious explanation is that AAs secrete more $\mathrm{GH}$, however, it has been suggested that GH secretion does not differ between AAs and EAs in childhood $(4,10)$.

Ethnic differences in physiologic variables could be related to environmental or genetic factors. Epidemiologic and clinical studies have detailed numerous environmental factors associated with systemic IGF-1 concentrations (11-13). Higher IGF-1 is associated with higher intake of total energy, carbohydrate, fat, and protein $(11,12)$. Adiposity and physical activity also may influence IGF-1 $(13,14)$. It is not known whether these variables contribute to the ethnic difference in IGF-1 during childhood. Conversely, ethnic differences in IGF-1 may 
have a genetic basis. The recently developed ancestral genetic admixture analysis can be used to assess genetic influences on physiologic variables that differ by ethnicity (15). Modern-day North Americans represent a population created by intermixing of European, African, and Native American populations. Hence, alleles from previously insulate populations were brought together in combinations that now encompass the gene pools of the various ethnic groups residing in North America. The relative contribution of parental population (e.g. African) to an individual's genome can be estimated using specific ancestry informative DNA markers that differ in frequency among the respective parental populations. Hence, assigning individuals an estimate of ancestral admixture, such as percentage AFADM, can help to delineate genetic from environmental influences on phenotypes that differ by ethnicity (15).

Therefore, we undertook the present analysis to determine whether diet, energy expenditure, SES, or adiposity contributed to the ethnic difference in systemic IGF-1 in childhood. In addition, to provide further insight into the influence of genetic factors on the ethnic difference in IGF-1, we assessed whether AFADM was an independent predictor of IGF-1. We hypothesized that ethnic differences in the nongenetic variables and/or adiposity would explain the higher IGF-1 of AA children. However, we found that the only independent predictors of IGF-1 were IGFBP-3 and AFADM, indicating a possible genetic basis for early ethnic differences in IGF-1.

\section{METHODS}

Sample. Data for our present analysis were derived from an ongoing longitudinal study of body fat distribution and disease risk factors in children and adolescents. Complete measures of dietary intake, energy expenditure, and body composition were available on 55 prepubertal children. Pubertal stage was determined by a pediatrician, according to the criteria of Tanner an Marshall (16,17). All children were prepubertal AAs (13 boys and 13 girls) and EAs ( 16 boys and 13 girls). Child ethnicity was assigned based on parental and grandparental ethnicity, i.e. both parents and all four grandparents had to be AA or EA for a child to be considered AA or EA, respectively. Children were recruited by word-of-mouth and newspaper advertisements. All participants recruited into this study were required to be greater than $4 \mathrm{y}$ of age and free of medications or disorders known to affect body composition, metabolism, or physical activity. The nature, purpose, and possible risks of the study were fully explained to parents before consent was obtained. All testing was undertaken at the University of Alabama at Birmingham (UAB) General Clinical Research Center (GCRC) and the Department of Nutrition Sciences. The study was approved by the Institutional Review Board for Human use at UAB. Written informed consent was obtained from parents and children before testing was initiated.

Energy expenditure assessment. Total free-living energy expenditure was determined over $14 \mathrm{~d}$ with the doubly labeled water technique as previously described (18). This method requires determination of the washout kinetics of isotopes of hydrogen $\left({ }^{2} \mathrm{H}_{2}\right)$ and oxygen $\left({ }^{18} \mathrm{O}_{2}\right)$, which are administered at baseline. $\mathrm{CO}_{2}$ production, an indirect measure of metabolic rate, is then determined as the difference in the disappearance rate of ${ }^{2} \mathrm{H}_{2}$ and ${ }^{18} \mathrm{O}_{2}$. This can be achieved because the rate of ${ }^{18} \mathrm{O}_{2}$ disappearance is influenced by both fluid loss and $\mathrm{CO}_{2}$ production, whereas the rate of ${ }^{2} \mathrm{H}_{2}$ disappearance is influenced predominantly by fluid loss. In brief, four-timed urine samples were collected after oral dosing with doubly labeled water, two samples were obtained in the morning after dosing and two in the morning $14 \mathrm{~d}$ later, with a loading dose of $0.15 \mathrm{~g}$ of $\mathrm{H}_{2}{ }^{18} \mathrm{O}$ and $0.12 \mathrm{~g}$ of ${ }^{2} \mathrm{H}_{2} \mathrm{O}$ per kilogram of body weight. Samples were analyzed in triplicate for $\mathrm{H}_{2}{ }^{18} \mathrm{O}$ and ${ }^{2} \mathrm{H}_{2} \mathrm{O}$ by isotoperatio mass spectrometry as previously described (18). Carbon dioxide production was then determined using the R2 equation of Speakman et al. (19), assuming a fixed dilution space ratio of 1.0427 , and energy expenditure was calculated using Equation 12 of de Weir, assuming the mean value of the dietary quotient was $0.9(20)$. This mean value for the food quotient of the subjects' diet was previously estimated from 24-h dietary recalls in this group.
This protocol has a theoretical error of $<5 \%$ for the measurement of total energy expenditure (18).

AEE was estimated as the difference between total energy expenditure and resting energy expenditure (REE), adjusted for the thermic effect of food $[\mathrm{AEE}=(0.9 * \mathrm{TEE})-\mathrm{REE}]$. REE was measured by indirect calorimetry using a Deltatrac Metabolic Monitor (Sensormedics Corp, Yorba Linda, CA). Subjects were awakened at $0500 \mathrm{~h}$, after an overnight stay at the GCRC, and instructed to lie in the supine position and remain motionless while an adult-sized canopy hood was used to collect expired gases. After a 10-min equilibration, oxygen consumption and carbon dioxide production data were collected continuously for $20 \mathrm{~min}$. REE was calculated using the equation of de Weir (20). In children, measurement of REE with the Deltatrac has been shown to be highly reliable (CV of $5.8 \%$ for six repeat measurements on six different days) and a single measurement is considered adequate to determine REE in children (21).

Blood sampling and hormone analysis. Fasting blood samples were obtained after measurement of REE. Serum samples were analyzed in duplicate for IGF-1 using a standard immunoradiometric assay (Diagnostic Systems Laboratories, Webster, TX; intra-assay CV was $3.7 \%$, inter-assay CV was 7.3\%) and in duplicate for IGFBP-3 using an immunoradiometric assay (Diagnostic Systems Laboratories; intra-assay CV was 4.0\%, inter-assay CV was $7.7 \%$ ). Serum estradiol was determined using a double-antibody RIA (Diagnostic Systems Laboratories; intra-assay CV was 3.6\%, inter-assay CV was $5.2 \%$ ). Serum testosterone was assessed using a solid phase RIA (Diagnostic Systems Laboratories; intra-assay CV was $2.7 \%$, inter-assay CV was $8.6 \%)$. Using these assays, the minimum detectable values of estradiol and testosterone were $4.2 \mathrm{pg} / \mathrm{mL}$ and $11.8 \mathrm{ng} / \mathrm{dL}$, respectively.

Body composition assessment. Body composition (total body fat mass and nonbone lean tissue mass) was measured by dual-energy x-ray absorptiometry (DXA) using a Lunar DPX-L densitometer (Lunar Radiation Corp., Madison, WI). Subjects were scanned in light clothing, while lying flat on their backs with arms at their sides. DXA scans were performed and analyzed with pediatric software version 1.5e. DXA has been found to be highly reliable for body composition assessment in children; in our laboratory, the $\mathrm{CV}$ for repeated measures of total body fat mass was $6.55 \%$. Height was measured to the nearest centimeter using a stadiometer, and weight was measured on an electronic scale while children wore light clothing.

Assessment of diet and socioeconomic status. Habitual intake of energy, protein, and fat was estimated from the average of three 24-h dietary recalls (one of which included a weekend day) using the multiple-pass technique in the presence of one or both parents. Each dietary recall was administered by a trained technician. The protocol was as follows: 1) a list of foods consumed in the previous $24 \mathrm{~h}$ was obtained; 2) details regarding the specific type of food and portion sizes consumed at each meal was determined; 3 ) lastly, a review was conducted to ensure that no food items consumed in the previous $24 \mathrm{~h}$ were excluded. The $24-\mathrm{h}$ recall method for assessing energy intake has been validated relative to the doubly labeled water method for assessment of energy expenditure in children. Comparisons of the mean energy intake and energy expenditure (assessed by doubly labeled water) did not differ significantly (22). Data were then entered into the Food Intake Analysis System (FIAS version 3.0, University of Texas, 1996) for determination macronutrient composition. The FIAS program is based on the US Department of Agriculture Nationwide Food Consumption Survey, Continuing Survey of Food Intakes by Individuals, and allows for the addition of new foods, recipe modification, and the selection of typical food portion sizes. The FIAS analysis provided average measures of total energy intake $(\mathrm{kcal} / \mathrm{d})$, protein intake $(\mathrm{g} / \mathrm{d})$, carbohydrate intake $(\mathrm{g} / \mathrm{d})$, saturated fat intake $(\mathrm{g} / \mathrm{d})$, and total fat intake $(\mathrm{g} / \mathrm{d})$. SES was determined according to the Hollingshead index of social status (23). This scale combined the education level and occupational prestige for the number of working parents in each child's family, accounting for sex and marital status. Social class scores using this scale range from 8 to 66; higher values represent a higher SES.

Determination of genetic admixture. Genotyping of study participants was carried out at the Pennsylvania State University. Genotyping of single nucleotide polymorphisms was carried out using agarose gel electrophoresis and melting curve analysis, where a fluorescent-labeled sequence-specific probe (SYBR Green I) is added during PCR that creates a heating-dependent melting curve for each polymorphism. DNA strand dissociation causes loss of fluorescence, which is a function of the PCR product length, its sequence composition, and its GC content. Melting curve analysis is described in detail by Akey et al. (24). The ancestry informative markers used, their chromosomal and centimorgan location, and their ability to discriminate among parental populations (based on the allelic differences between European and African parental populations) are detailed in Table 1 and are described elsewhere (25). Further information about these markers is available through dbSNP (http:// www.ncbi.nlm.nih.gov/projects/SNP/) using handle PSA-ANTH. All genetic data were transformed into a single estimate of genetic admixture using the 
Table 1. Ancestry informative DNA markers used in the determination of African genetic admixture, their location, and frequency difference $(\delta)$ among parental populations

\begin{tabular}{|c|c|c|c|}
\hline Marker & Chromosomal location & $\mathrm{cM}$ & $\delta\left(\right.$ AA vs. $\left.\mathrm{EA}^{1}\right)$ \\
\hline MID 575 & $1 \mathrm{p} 34.3$ & $\sim 64$ & 0.130 \\
\hline MID 187 & $1 \mathrm{p} 34.1$ & $\sim 75$ & 0.370 \\
\hline FY-Null & $1 q 23.2$ & $\sim 165$ & 0.999 \\
\hline AT3 & $1 \mathrm{q} 25.1$ & $\sim 191$ & 0.575 \\
\hline WI-11392 & $1 \mathrm{q} 42.2$ & $\sim 252$ & 0.444 \\
\hline WI- 18657 & $2 \mathrm{p} 16.1$ & $\sim 79$ & 0.536 \\
\hline WI- 11153 & $3 \mathrm{p} 12.3$ & $\sim 106$ & 0.652 \\
\hline $\mathrm{GC} * 1 \mathrm{~F}$ & $4 q 13.3$ & 79 & 0.697 \\
\hline $\mathrm{GC} * 1 \mathrm{~S}$ & $4 q 13.3$ & 79 & 0.538 \\
\hline SGC30055 & $5 \mathrm{q} 23.1$ & $\sim 120$ & 0.457 \\
\hline CYP3A4 & $7 q 22.1$ & $\sim 111$ & 0.761 \\
\hline LPL & $8 \mathrm{p} 21.3$ & $\sim 398$ & 0.479 \\
\hline D11S429 & $11 \mathrm{q} 11$ & $\sim 70.9$ & 0.429 \\
\hline DRD2-Taq1"D" & $11 \mathrm{q} 23.1$ & $\sim 105$ & 0.535 \\
\hline APOA1 & $11 \mathrm{q} 23.3$ & $\sim 113$ & 0.505 \\
\hline GNB3 & $12 \mathrm{p} 13.31$ & $\sim 15$ & 0.463 \\
\hline OCA2 & $15 \mathrm{q} 13.1$ & $\sim 16$ & 0.631 \\
\hline MC1R314 & $16 \mathrm{q} 24.3$ & $\sim 133$ & 0.350 \\
\hline WI-14867 & $17 \mathrm{p} 13.2$ & $\sim 10$ & 0.448 \\
\hline WI-7423 & $17 \mathrm{p} 12$ & $\sim 16$ & 0.476 \\
\hline Sb19.3 & 19p13.11 & $\sim 49$ & 0.488 \\
\hline MID154 & $20 q 11.22$ & $\sim 50$ & 0.444 \\
\hline
\end{tabular}

${ }^{1}(\delta)$ Allelic frequency difference between West African and European parental populations; calculated as the frequency of marker allele in West African populations minus the frequency in European populations.

maximum likelihood approach (26) such that the likelihood that a particular multilocus genotype is from each of 100 different combinations of the two parental populations is calculated as the probability of the genotype given the allele frequencies in each parental population. The parental population combination where the specific multilocus genotype for an individual has the highest probability is thus the most likely and represents the admixture estimate for that individual.

Statistics. Two-way ANOVA was used to assess potential effects of ethnicity and gender on the variables analyzed. Relations between IGF-1 and dietary, activity, and other outcome variables were assessed using Pearson correlation coefficients. Independent associations of genetic, lifestyle, and physiologic variables with IGF-1 were assessed using multiple linear regression analysis. All data were log transformed to correct for skewed distribu- tions. Statistical significance was set at $p<0.05$ for all analyses. Data were analyzed using SPSS for Windows version 10.0 (SPSS Inc., Chicago, IL).

\section{RESULTS}

IGF-1 concentrations were significantly higher in AA children compared with EA children (Table 2). Girls had significantly higher IGF-1 concentrations than boys; there was no interaction between gender and ethnicity (Table 2). Girls also had significantly higher IGFBP-3 concentrations than boys; no ethnic difference in IGFBP-3 was noted. SES was significantly lower in AA children and total protein intake was higher. There were no ethnic or gender differences in age, height, weight, fat mass, energy intake, fat intake, or AEE (Table 2). Two boys (one AA, one EA) had serum testosterone concentrations above the detectable limit and one AA girl had a serum estradiol concentration above the detectable limit. There were no ethnic or gender differences in concentrations of sex hormones (Table 2) and all children were prepubertal (Tanner stage one).

Pearson correlation coefficients for IGF-1 are presented in Table 3. SES was negatively associated with IGF-1. AFADM, IGFBP-3, fat mass, and AEE were significantly and positively correlated with IGF-1. There were no significant correlations between IGF-1 and the dietary intake variables.

Results from the multiple regression analysis for the dependent variable IGF-1 are presented in Table 4. Variables that were significantly correlated with IGF-1 or were significantly different between ethnicities were added to the final multiple regression model. Hence, independent variables in the analysis were AFADM, fat mass, protein intake, SES, AEE, and IGFBP-3. The only variables independently associated with IGF-1 were AFADM $(p<0.01)$ and IGFBP-3 $(p<0.01)$; the $R^{2}$ value for the model was 0.59 . Addition of gender to the model did not affect the independent association of IGF-1 with AFADM (data not shown).

\section{DISCUSSION}

We tested the hypothesis that the higher concentrations of systemic IGF-1 in AA children compared with EA children were related to environmental and body composition variables known to be associated with IGF-1. AA and EA children did not differ significantly by age, body weight or height, pubertal stage, or sex hormone concentrations. Contrary to our hypothesis, we found that neither diet, physical activity, SES, nor adiposity were related to the higher IGF-1 of AA children. Results indicated that AFADM and IGFBP-3 were the only independent predictors of IGF-1 in our sample. IGFBP-3 has a strong influence on systemic IGF-1 because it binds the ligand

Table 2. Subject characteristics $*$ Mean $\pm S D$

\begin{tabular}{|c|c|c|c|c|c|}
\hline & EA $(n=29)$ & AA $(n=26)$ & Ethnicity $\dagger$ & Gender $\dagger$ & Ethnicity $\times$ gender \\
\hline Age (yrs.) & $7.9 \pm 2.0$ & $8.3 \pm 1.4$ & NS & NS & NS \\
\hline Weight $(\mathrm{kg})$ & $32.3 \pm 7.4$ & $36.6 \pm 12.4$ & NS & NS & NS \\
\hline Height $(\mathrm{cm})$ & $131.5 \pm 8.9$ & $134.8 \pm 9.7$ & NS & NS & NS \\
\hline IGF-1 (ng/mL)** & $190.8 \pm 79.3$ & $258.2 \pm 100.2$ & $<0.01$ & $<0.05$ & NS \\
\hline IGFBP3 $(\mathrm{ng} / \mathrm{mL})^{* *}$ & $3791 \pm 794$ & $3939 \pm 621$ & NS & $<0.05$ & NS \\
\hline Testosterone (ng/dL) & $11.87 \pm 0.47$ & $11.84 \pm 0.23$ & NS & NS & NS \\
\hline Energy (Kcal/d) & $1854 \pm 501$ & $1858 \pm 525$ & NS & NS & NS \\
\hline Carbohydrate $(\mathrm{g} / \mathrm{d})$ & $260.4 \pm 83.2$ & $225.5 \pm 80.7$ & NS & NS & NS \\
\hline Protein $(\mathrm{g} / \mathrm{d})$ & $58.9 \pm 19.9$ & $76.9 \pm 37.7$ & $<0.05$ & NS & NS \\
\hline Fat $(g / d)$ & $66.6 \pm 23.2$ & $74.9 \pm 26.1$ & NS & NS & NS \\
\hline Saturated fat $(\mathrm{g} / \mathrm{d})$ & $23.3 \pm 7.7$ & $26.9 \pm 13.6$ & NS & NS & NS \\
\hline $\operatorname{AEE}(\mathrm{Kcal} / \mathrm{d})$ & $667.5 \pm 1152$ & $663.6 \pm 382$ & NS & NS & NS \\
\hline
\end{tabular}

* Statistical comparisons were conducted with log transformed data to correct for skewed distributions; untransformed mean \pm SD are presented for ease of interpretation.

$\dagger P$-values for 2-way ANOVA for ethnicity, gender, and the interaction between ethnicity and gender. NS $=$ not significant $(P>0.05)$.

** To convert metric units $(\mathrm{ng} / \mathrm{mL})$ to SI units (nmol/l) for IGF-1 multiply by 0.131 , for IGFBP-3 multiply by 0.035 . 
Table 3. Pearson correlation coefficients for the relation between $I G F-1$ and dietary, lifestyle, and physiologic variables*

\begin{tabular}{lrc}
\hline & $r$ & $P$ \\
\hline Age & 0.12 & 0.37 \\
IGFBP-3 & 0.70 & $<0.001$ \\
SES & -0.29 & $<0.05$ \\
Energy & 0.02 & 0.89 \\
Carbohydrate & -0.09 & 0.52 \\
Protein & 0.09 & 0.49 \\
Fat & 0.14 & 0.31 \\
Saturated fat & 0.02 & 0.91 \\
Fat mass & 0.35 & $<0.01$ \\
AEE & 0.27 & $<0.05$ \\
AFADM & 0.35 & $<0.01$ \\
\hline
\end{tabular}

* Analyses were conducted with log-transformed data to correct for skewed distributions.

Table 4. Independent predictors of serum total IGF-1 from multiple linear regression analysis $*,+$, variables excluded from model are described below

\begin{tabular}{crr}
\hline & \multicolumn{1}{c}{$\beta \pm$ SEE } & $P$ \\
\hline Intercept & $-3.47 \pm 0.72$ & $<0.001$ \\
AFADM & $0.014 \pm 0.00$ & 0.001 \\
IGFBP-3 & $1.59 \pm 0.20$ & $<0.001$ \\
\hline
\end{tabular}

* Analyses were conducted with log-transformed data to correct for skewed distributions.

$\mathrm{R}^{2}$ for the model $=0.578$. Variables excluded from the model at $P>0.05$ : SES $(P=0.38)$; fat mass $(P=0.62)$; protein $(P=0.90)$; AEE $(P=0.47)$.

$\dagger$ Gender did not influence the independent association of AFADM with IGF-1 (data not shown).

and increases its half-life. The association of AFADM with systemic IGF-1 suggests that higher IGF-1 in AAs relative to EAs may have a genetic basis.

Associations between disease and elevated concentrations of IGF-1 have been documented in adults $(2,3)$. Furthermore, indices of childhood growth such as leg length have been linked to the development of hormone-related cancers such as those of the prostate and breast (27). It has been suggested that growth-promoting factors such as IGF-1 could mediate the link between growth and later cancer risk (28). The prevalence of prostate cancer is known to be higher in AA men (29), and AA women are more likely to have a more advanced breast tumors compared with EA women (30). High growth rates during childhood are also associated with later development of obesity and cardiovascular disease risk profiles $(31,32)$. Obesity and cardiovascular-related morbidity such as stroke have higher prevalence rates in AAs compared with EAs (33). Whether IGF-1 differences in during childhood directly or indirectly contribute to ethnic differences in disease risk is unknown.

Systemic IGF-1 may be affected by diet and physical activity (14). The mechanism underlying the relation between physical activity and IGF-1 is not known but may be related to effects on energy and nitrogen balance, or on IGFBP regulation (14). A low-fat diet combined with a daily exercise intervention has been shown to decrease IGF-1 independent of IGFBP-3 concentrations in older men (13). Studies have shown that exercise and physical activity either have no association with, or are associated with both higher and lower IGF-1 (13,34-36). Although we found a positive association between IGF-1 and
AEE, our data suggest that differences in energy expenditure are not responsible for the ethnic difference in IGF-1.

Epidemiologic studies have demonstrated that higher energy, protein, and fat intakes are associated with higher IGF-1 $(11,12,37)$, however, in one study dietary factors were not associated with IGF-1 in children (38). Dietary influences on IGF-1 production could be direct, or indirect, via macronutrient influences on GH secretion or IGFBP regulation; the actual mechanism(s) is unknown $(14,36)$. We did not find that differences in total energy, protein, or fat intake were related to the higher IGF-1 of AA relative to EA children.

Adiposity has also been associated with IGF-1 in adults and children $(14,39)$, and fat mass was positively correlated with IGF-1 in our study. However, we did not find fat mass to have an influence on the ethnic difference in IGF-1. Our observations suggest that physical activity, macronutrient intake, SES, and adiposity are not responsible for the ethnic difference in systemic IGF-1.

Measures of AFADM yield some insight into the influence of genetic versus environmental factors on ethnic differences in physiologic outcomes. In this study, AFADM independently predicted systemic IGF-1, suggesting that the higher IGF-1 of AAs compared with EAs may be attributable to genetic differences. Polymorphisms in several genes have been associated with systemic IGF-1 (9). Polymorphisms in the promoter region of the IGF-1 gene and in the promoter region of the gene for the cytochrome P450 3A4 enzyme have been shown to account for the higher IGF-1 of premenopausal AA women relative to EA women, however, this effect was only observed in those using oral contraceptives (9). It is not known whether any of these polymorphisms explain the ethnic differences in IGF-1 during childhood.

Differences in maturation rate could be responsible for a portion of the ethnic difference in IGF-1. AA children, particularly girls, enter into puberty on average $1 \mathrm{y}$ earlier than EA children (40). IGF-1 concentrations rise in response to rising $\mathrm{GH}$ and sex-steroid hormone concentrations at the beginning of puberty. Hence, it is possible that the higher concentrations of IGF-1 in the prepubertal AA compared with EA children of this study reflected their greater proximity to puberty. Although the two groups did not differ with respect to concentrations of sex hormones, subtle differences in hormone concentrations may not have been detected.

Conversely, as GH and/or IGF-1 may play a role in the timing of puberty onset; higher IGF-I among AA children may contribute to their earlier maturation. This theory is supported by observations that, relative to boys, girls have both a higher concentration of IGF-I before puberty (38), and an earlier age of pubertal onset. In agreement with this previous observation, the girls in the present study had higher IGF-I than the boys. Whether higher IGF-I among AA children is a cause or consequence of earlier puberty requires further investigation.

There are several limitations to our study. These include sample size, and questionnaire-based measures of macronutrient intake and SES. Given that our study was cross-sectional in design and our sample size was limited to $n=54$, our findings of the absence of an environmental component in the ethnic difference in IGF-1 should be considered tentative until these 
findings can be replicated in a larger sample. Indeed, unmeasured environmental parameters may also have contributed to the higher IGF-1 of AA. In addition, because questionnaire and other recall-based assessments may have limited accuracy, the contribution of these variables to the higher IGF-1 of AAs relative to EAs cannot be completely ruled out. Furthermore, since IGF-1 concentrations are strongly influenced by GH, the higher IGF-1 of AAs could be related to higher GH secretion or action. Although GH secretion has not been shown to be greater in AA children compared with EA children, the sample studied comprised only a small number of males (10); therefore, higher GH cannot be completely discounted as the cause of the higher IGF- 1 concentrations. Unfortunately, robust analysis of GH secretion, which requires frequent blood sampling throughout the day, was not available in our study. Further studies with larger samples sizes and accurate measures of GH release are needed to clarify this issue.

In conclusion, we found an independent association of AFADM with IGF-1. Hence, this ethnic difference could be related to genetic factors, perhaps via polymorphisms of genes directly regulating the $\mathrm{GH} / \mathrm{IGF}$ system or regulating maturation rate. However, further work will be required to conclusively test these hypotheses. The effect of higher childhood IGF-1 concentrations on disease risk in this population remains to be determined.

Acknowledgments. The authors thank Tena Hilario-Hailey and the VICTORY study team for subject recruitment, study coordination, and data management, and the laboratory of Dr. Mark Shriver at the Pennsylvania State University for genotyping of ancestry informative markers. We also thank Betty Darnell for performing anthropometric measures, and the nurses and staff of the GCRC.

\section{REFERENCES}

1. Le Roith D 1997 Insulin-like growth factors. N Eng J Med 336:633-640

2. Homburg R, Pariente C, Lunenfeld B, Jacobs HS 1992 The role of insulin-like growth factor-1 (IGF-1) and IGF binding protein-1 (IGFBP-1) in the pathogenesis of polycystic ovary syndrome. Hum Reprod 7:1379-1383

3. LeRoith D, Roberts CT Jr 2003 The insulin-like growth factor system and cancer. Cancer Lett 195:127-137

4. Yanovski JA, Sovik KN, Nguyen TT, Sebring NG 2000 Insulin-like growth factors and bone mineral density in African American and white girls. J Pediatr 137:826-832

5. Girgis R, Abrams SA, Castracane VD, Gunn SK, Ellis KJ, Copeland KC 2000 Ethnic differences in androgens, IGF-1, and body fat in healthy prepubertal girls. J Pediatr Endocrinol Metab 13:497-503

6. Ku CY, Gower BA, Hunter GR, Goran MI 2000 Racial differences in insulin secretion and sensitivity in prepubertal children: role of physical fitness and physical activity. Obes Res 8:506-515

7. Winter DL, Hanlon AL, Raysor SL, Watkins-Bruner D, Pinover WH, Hanks GE, Tricoli JVWH 2001 Plasma levels of IGF-1, IGF-2, and IGFBP-3 in white and African American men at increased risk of prostate cancer. Urology 58:614-618

8. Aloia JF, Mikhail M, Pagan CD, Arunachalam A, Yeh JK, Flaster E 1998 Biochemical and hormonal variables in black and white women matched for age and weight. J Lab Clin Med 132:383-389

9. Jernstrom H, Chu W, Vesprini D, Tao Y, Majeed N, Deal C, Pollak M, Narod SA 2001 Genetic factors related to racial variation in plasma levels of insulin-like growth factor-1: implications for premenopausal breast cancer risk. Mol Genetics Metab 72:144-154

10. Wright NM, Papadea N, Veldhuis JD, Bell NH 2002 Growth hormone secretion and bone mineral density in prepubertal black and white boys. Calcif Tissue Int 70:146152
11. Heald AH, Cade JE, Cruickshank JK, Anderson S, White A, Gibson JM 2003 The influence of dietary intake on insulin-like growth factor (IGF) system across three ethnic groups: a population based study. Public Health Nutr 6:175-180

12. Gunnell D, Oliver SE, Peters TJ, Donovan JL, Persad R, Maynard M, Gillatt D, Pearce A, Hamdy FC, Neal DE, Holly JM 2003 Are diet-prostate cancer associations mediated by the IGF axis? A cross sectional analysis of diet, IGF-1, and IGFBP-3 in healthy middle-aged men. Br J Cancer 88:1682-1686

13. Ngo TH, Barnard RJ, Tymchuk CN, Cohen P, Aronson WJ 2002 Effect of diet and exercise on serum insulin, IGF-1, and IGFBP-1 levels and growth of LNCaP cells in vitro (United States). Cancer Causes and Control 13:929-935

14. Thissen JP, Ketelslegers JM, Underwood LE 1994 Nutritional regulation of the insulin-like growth factors. Endocr Rev 15:80-101

15. Fernandez JR, Shriver MD 2004 Using genetic admixture to study the biology of obesity traits and to map genes in admixed populations. Nutr Rev 62:S69-S74

16. Marshall WA, Tanner JM 1969 Variations in the pattern of pubertal changes in girls. Arch Dis Child 44:291-303

17. Marshall WA, Tanner JM 1970 Variations in the pattern of pubertal changes in boys Arch Dis Child 45:13-23

18. Goran MI, Carpenter WH, McGloin A, Johnson R, Hardin JM, Weinsier RL 1995 Energy expenditure in children of lean and obese parents. Am J Physiol 268:E917E924

19. Speakman JR, Nair KS, Goran MI 1993 Revised equations for calculating CO2 production from doubly labeled water in humans. Am J Physiol 264:E912-E917

20. Weir JB 1949 New methods for calculating metabolic rate with special reference to protein metabolism. J Physiol 109:1-9

21. Figueroa-Colon R, Franklin FA, Goran MI, Lee JY, Weinsier RL 1996 Reproducibility of measurement of resting energy expenditure in prepubertal girls. Am J Clin Nutr 64:533-536

22. Lindquist $\mathrm{CH}$, Cummings T, Goran MI 2000 Use of tape-recorded food records in assessing children's dietary intake. Obes Res 8:2-11

23. Hollingshead AB 1975 Four-Factor Index of Social Status. Yale University Press, New Haven, CT, pp 4-21

24. Akey JM, Sosnoski D, Parra E, Dios S, Hiester K, Su B, Bonilla C, Jin L, Shriver MD 2001 Melting curve analysis of SNPs (McSNP): a gel free and inexpensive approach for SNP genotyping. Biotechniques 30:358-367

25. Parra EJ, Marcini A, Akey J, Martinson J, Batzer MA, Cooper R, Forrester T, Allison DB, Deka R, Ferrell RE, Shriver MD 1998 Estimating African American admixture proportions use of population-specific alleles. Am J Hum Genet 63:241-251

26. Hanis CL, Chakraborty R, Ferrell RE, Schull WJ 1986 Individual admixture estimates: disease associations and individual risk of diabetes and gall bladder disease among Mexican-Americans in Starr County, Texas. Am J Physiol Anthropol 70:433441

27. Gunnell DJ, Smith GD, Holly JM, Frankel S 1998 Leg length and risk of cancer in the Boyd Orr cohort. BMJ 317:1350-1351

28. Gunnel D, Oliver SE, Donovan JL, Peters TJ, Gillatt D, Persad R, Hamdy FC, Neal DE, Holly JM 2004 Do height-related variations in insulin-like growth factors underlie the associations of stature with adult chronic disease. J Clin Endocrinol Metab 89:213-218

29. Greenlee RT, Murray T, Bolden S, Wingo PA 2000 Cancer statistics 2000. CA Cancer J Clin 50:7-33

30. Ghafoor A, Jemal A, Ward E, Cokkinides V, Smith R, Thun M 2003 Trends in breast cancer by race and ethnicity. CA Cancer J Clin 53:342-355

31. Sinaiko AR, Donahue RP, Jacobs DR Jr., Prineas RJ 1999 Relation of weight and rate of increase in weight during childhood and adolescence to body size, blood pressure, fasting insulin, and lipids in young adults. Circulation 99:1471-1476

32. Adair LS, Cole TJ 2003 Rapid child growth raises blood pressure in adolescent boys who are thin at birth. Hypertension 41:451-456

33. Cossrow N, Falkner B 2004 Race/ethnic issues in obesity and obesity-related comorbidities. J Clin Endocrinol Metab 89:2590-2594

34. Poehlman ET, Copeland KC 1990 Influence of physical activity on insulin-like growth factor 1 in healthy younger and older men. J Clin Endocrinol Metab 71:1468-1473

35. Felsing NE, Brasel JA, Cooper DM 1992 Effect of low and high intensity exercise on circulating growth hormone in men. J Clin Endocrinol Metab 75:157-162

36. Voskuil DW, Bueno de Mesquita HB, Kaaka R, van Noord PA, Rinaldi S, Riboli E, Grobbee DE, Peeters PH 2001 Determinants of circulating insulin-like growth factor (IGF)-1 and IGF binding proteins 1-3 in premenopausal women: physical activity and anthropometry (Netherlands). Cancer Causes Control 12:951-958

37. Giovannucci E, Pollak M, Liu Y, Platz EA, Majeed N, Rimm EB, Willett WC 2002 Nutritional predictors of insulin-like growth factor I and their relationships to cancer in men. Cancer Epidemiol Biomarkers Prev 12:84-89

38. Wilson DM, Killen JD, Hammer LD, Litt IF, Vosti C, Miner B, Hayward C, Taylor CB 1991 Insulin-like growth factor-1 as a reflection of body composition, nutrition, and puberty in sixth and seventh grade girls. J Clin Endocrinol Metab 73:907-912

39. L'Allemand D, Schmidt S, Rousson V, Brabant G, Gasser T, Gruters A 2002 Associations between body mass, leptin, IGF-1, and circulating adrenal androgens in children with obesity and premature adrenarche. Eur J Endocrinol 146:537-543

40. Wu T, Mendola P, Buck GM 2002 Ethnic difference in the presence of secondary sex characteristics and menarche among US girls: the Third National Health and Nutrition Examination Survey, 1988-1994. Pediatrics 110:752-757 